\title{
Hydroalcoholic and Alkaloidal Extracts of Murraya koenigii (L.) Spreng Augments Glucose Uptake Potential against Insulin Resistance Condition in L6 Myotubes and Inhibits Adipogenesis in 3T3L1 Adipocytes
}

\author{
Parameswari Royapuram Parthasarathy', Janani Murthy' ${ }^{1}$ Dinesh Murugan Girija', Srivani Telapolu', \\ Chamundeeswari Duraipandian², Thyagarajan Sadras Panchatcharam ${ }^{3 *}$
}

\section{Parameswari Royapuram Parthasarathy ${ }^{1}$, Janani Murthy', Dinesh Murugan Girija1', Srivani Telapolu', Chamundeeswari Durai- pandian ${ }^{2}$, Thyagarajan Sadras Panchatcharam ${ }^{3 *}$}

'SRMC Centre for Indian Systems of Medicine, Quality assurance and Standardization, Central Research Facility, Sri Ramachandra University, Porur, Chennai, Tamil Nadu, INDIA. 2Department of Pharmacognosy, Faculty of Pharmacy, Sri Ramachandra University, Porur, Chennai, Tamil Nadu, INDIA.

${ }^{3}$ Central Research Facility, Sri Ramachandra University, Porur, Chennai, Tamil Nadu, INDIA.

Correspondence

Thyagarajan Sadras Panchatcharam

Central Research Facility, Sri Ramachandra University, Porur, Chennai - 600 116, Tamil Nadu, INDIA.

Phone: 044 - 45928665

E-mail: deanresearch@sriramachandra. edu.in

History

- Submission Date: 06-11-2017;

- Review completed: 22-12-2017;

- Accepted Date: 03-01-2018

DOI : 10.5530/pj.2018.4.104

Article Available online

http://www.phcogj.com/v10/i4

\section{Copyright}

(C) 2018 Phcog.Net. This is an openaccess article distributed under the terms of the Creative Commons Attribution 4.0 International license.

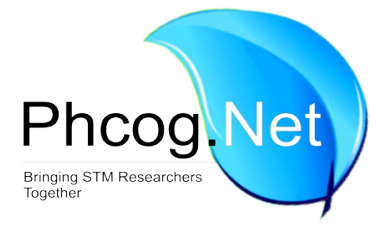

\begin{abstract}
Background: Murraya koenigii, commonly known as "curry leaves" is native to India. The highly valued part of the plant is the leaves which possess various biological activities. Objective: The present study aimed to investigate the antidiabetic effect of Murraya koenigii (MK) leaf extracts, of two different solvent ratios. Materials and methods: $70 \%$ hydroalcoholic and alkaloidal extracts of MK leaves were prepared by cold maceration method. Preliminary phytochemical analysis was carried out for both the extracts. In vitro anti diabetic activity was screened by inhibitory action on $\alpha$ - amylase, $\alpha$ - glucosidase enzymes. Further, the $70 \%$ hydroalcoholic and alkaloidal extracts were assessed for glucose uptake potential, anti - adipogenic property, as well as inhibitory activity on diabetes associated complications. HPTLC quantification of major phytoconstituent was carried out. Results: The study showed presence of various phytoconstituents such as, polyphenols, alkaloids, tannins, reducing sugars etc. The $70 \%$ hydroalcoholic and alkaloidal extracts of MK leaves exhibited $>90 \%$ inhibition against carbohydrate metabolising enzymes compared to aqueous and absolute alcohol extracts. Both the extracts showed enhanced glucose uptake in L6 myotubes attenuating the effect of Palmitate induced insulin resistance. Significant inhibition on adipogenesis was exerted by both $70 \%$ hydroalcoholic and alkaloidal extracts of MK leaves. Besides, marked inhibition of advanced glycation end products was exhibited by the extracts. HPTLC quantification analysis of the aforementioned extracts showed the presence of major phytoconstituent, Mahanine, in it. Conclusion: The results of the present study showed that MK possesses significant antidiabetic property and also exhibited considerable effect in preventing diabetes associated complications. The potent antidiabetic activity of MK could be attributed to the presence of Mahanine, the major active constituent, which is a carbazole alkaloid.

Key words: Diabetes, Mahanine, $\alpha$-amylase, glucose uptake, L6 myotubes, complications.
\end{abstract}

\section{INTRODUCTION}

Insulin resistance (IR) is a key contributor for the onset of obesity and type 2 diabetes (T2D). IR is considered as pre - diabetic state, manifested by reduced insulin sensitivity and decreased glucose uptake in peripheral tissues such as skeletal muscle and adipocytes with increased hepatic glucose production, resulting in defective insulin secretion. ${ }^{1}$ The imbalanced condition of elevated hepatic glucose production, reduced insulin secretion and compromised insulin action comprehensively lead to oxidative stress which ultimately paves way to long - term complications such as, cardiovascular disease, diabetic retinopathy, diabetic nephropathy and neuropathy. ${ }^{2}$ Therefore drugs that can counteract IR have become the focus of research for the management of T2D. Subsequent to develop- ment of unwanted and severe side- effects on long - term usage of various classes of oral hypoglycemic agents and insulin secretagogues, dependence on medicinal plants enriched with bioactive phytoconstituents has geared during recent years to counteract the effects of IR. ${ }^{3}$

Murraya koenigii (Linn.) Spreng, belonging to Rutaceae family, known commonly as Curry leaves in English is used as an edible spice in Indian kitchens; it possesses significant medicinal values and has been used in traditional medicine either in isolation or in formulations. ${ }^{4}$ The plant is enriched with carbazole alkaloids such as, Mahanine, Mahanimbicine, Mahanimbine and essential oil. ${ }^{5}$ The aerial part of MK has been prescribed for diabetes in Ayurveda

Cite this article: Parameswari RP, Janani M, Dinesh, MG, Srivani T, Chamundeeswari D, Thyagarajan SP. Hydroalcoholic and Alkaloidal Extracts of Murraya koenigii (L.) Spreng Augments Glucose Uptake Potential against Insulin Resistance Condition in L6 Myotubes and Inhibits Adipogenesis in 3T3L1 Adipocytes. Pharmacog J. 2018;10(4):633-9 
systems of medicine. ${ }^{6}$ The crude leaf extract of MK was reported for its antioxidant, ${ }^{7}$ anti - bacterial, ${ }^{8}$ anti - inflammatory, ${ }^{9}$ and topo-isomerases inhibition. ${ }^{10}$ While studies have revealed the anti - diabetic property of $\mathrm{MK}^{11,12,13}$ inconsistent results on the effect of MK extracts have also been reported. ${ }^{14,15,16}$ In the present study, we show reduced hyperglycemia and amelioration of insulin sensitivity induced by fatty acid Palmitate and adipogenic inhibitory action of two different solvent ratio Murraya koenigii leaf extracts, besides preventing from diabetes associated complication.

\section{MATERIALS AND METHODS}

\section{Collection of plant material and authentication}

The leaves of Murraya koenigii was collected from Tirunelveli district by Dr. V. Chelladurai, Retd Research officer, CCRAS. The leaves were authenticated by Prof. P. Jayaraman, Plant Anatomist Botanists, Plant Anatomy Research Centre, Tambaram (PARC/ 2015/3167). Further, the leaves were washed thoroughly, shade dried and ground into coarse powder.

\section{Preparation of Extracts}

Extraction of leaf $(1 \mathrm{~g})$ involved cold maceration with $70 \%$ ethanol and $30 \%$ chloroform in methanol for $72 \mathrm{~h}$ and the filtrate was collected. Filtered contents were distilled, evaporated and concentrated in rotary vacuum evaporator at $60^{\circ} \mathrm{C}$. The extracts were used for chemo profiling and further in vitro assays.

\section{Phytochemical analysis}

Qualitative phytochemical analysis was carried out for 70\% hydroalcoholic and alkaloidal extracts of Murraya koenigii as per the method of Harbone, 1984.

\section{a- amylase inhibitory activity}

In vitro amylase inhibition was studied by the method of Bernfeld, $1955 .{ }^{17}$ Briefly, $100 \mu \mathrm{L}$ of different concentrations $(1,3,10,30,100,300$ and $1000 \mu \mathrm{g} / \mathrm{ml}$ ) $70 \%$ hydroalcoholic (HA) and alkaloidal MK extracts could react with $200 \mu$ of $\alpha$-amylase enzyme (Hi media RM 638) and $100 \mu \mathrm{L}$ of $2 \mathrm{mM}$ of phosphate buffer ( $\mathrm{pH}-6.9$ ). After 20-min incubation, $100 \mu \mathrm{l}$ of $1 \%$ starch solution was added. The same was performed for the controls where $200 \mu \mathrm{l}$ of the enzyme was replaced by buffer. After incubation for $5 \mathrm{~min}, 500 \mu \mathrm{l}$ of Dinitrosalicylic acid reagent was added to both control and test. They were kept in boiling water bath for $5 \mathrm{~min}$. The absorbance was recorded at $540 \mathrm{~nm}$ using spectrophotometer and the percentage inhibition of $\alpha$-amylase enzyme was calculated using the formula:

$$
\% \text { inhibition }=\frac{(\text { Control }- \text { Test })}{\text { Control }} \times 100
$$

Suitable reagent blank and inhibitor controls were simultaneously carried out.

\section{a-glucosidase inhibitory activity}

The enzyme inhibition activity for $\alpha$-glucosidase was evaluated according to the method previously reported by Shruti et al. (2011) with minor modifications. ${ }^{18}$ The reaction mixture consisted of $50 \mu \mathrm{L}$ of $0.1 \mathrm{M}$ phosphate buffer (with $\mathrm{pH}$ of 7.0), $25 \mu \mathrm{L}$ of $0.5 \mathrm{mM} 4$-nitrophenyl $\alpha$-D-glucopyranoside (dissolved in $0.1 \mathrm{M}$ phosphate buffer, with $\mathrm{pH}$ of 7.0 ), $10 \mu \mathrm{L}$ of different concentrations $(1,3,10,30,100,300$ and $1000 \mu \mathrm{g} / \mathrm{ml}) 70 \%$ hydroalcoholic (HA) and alkaloidal $\mathrm{MK}$ extracts and $25 \mu \mathrm{L}$ of $\alpha$-glucosidase solution (a stock solution of $1 \mathrm{mg} / \mathrm{mL}$ in $0.01 \mathrm{M}$ phosphate buffer, with $\mathrm{pH}$ of 7.0 was diluted to $0.1 \mathrm{Unit} / \mathrm{mL}$ with the same buffer, with $\mathrm{pH}$ of 7.0 just before assay). This reaction mixture was then incubated at $37^{\circ} \mathrm{C}$ for $30 \mathrm{~min}$. Then, the reaction was terminated by the addition of $100 \mu \mathrm{L}$ of
$0.2 \mathrm{M}$ sodium carbonate solution. The enzymatic hydrolysis of substrate was monitored by the amount of p-nitrophenol released in the reaction mixture at $410 \mathrm{~nm}$ using microplate reader. Individual blanks were prepared for correcting the background absorbance, where the enzymes were replaced with buffer. Controls were conducted in an identical manner replacing the plant extracts with methanol. Acarbose was used as positive control. All experiments were carried out in triplicates.

\section{Cell Culture Studies}

Preparation of cell culture

L6, a monolayer myoblast culture (obtained from NCCS, Pune - Passage no- 15) and 3T3L1 pre-adipocytes (obtained from NCCS, Pune - Passage no - 19) were cultured in DMEM with $10 \%$ foetal bovine serum (FBS) and supplemented with penicillin (120units $/ \mathrm{ml})$, streptomycin $(75 \mu \mathrm{g} / \mathrm{ml})$, gentamycin $(160 \mu \mathrm{g} / \mathrm{ml})$ and amphotericin B $(3 \mu \mathrm{g} / \mathrm{ml})$ in a $5 \% \mathrm{CO} 2$ environment. For differentiation, the L6 cells were transferred to DMEM with $2 \%$ FBS for 4 days, post-confluence. The extent of differentiation was established by observing the multinucleate of cells. 3T3L1 pre-adipocytes grown in 48 well plates until 2 days post-confluence and the cells were induced by the differentiation medium (combination of $0.5 \mathrm{mM} / 1$ of IBMX, $0.25 \mu \mathrm{M} / \mathrm{l}$ of DEX and $1 \mathrm{mg} / \mathrm{l}$ of insulin in DMEM medium with $10 \%$ FBS) to differentiate into adipocytes. Three days after induction, the differentiation medium was replaced with medium containing $1 \mathrm{mg} / \mathrm{ml}$ insulin alone. The medium was subsequently replaced again with fresh culture medium (DMEM with 10\% FBS) after 2 days the extent of differentiation was measured by monitoring the formation of multi nucleation in cells.

\section{Measurement of 2-deoxy-D-[1-3 $H]$ glucose ${ }^{19}$}

L6 myoblasts grown in 24 well plate was subjected to glucose uptake as reported by Anand et al., 2010. In brief, differentiated cells were serum starved for $5 \mathrm{~h}$ and were incubated with different concentrations $(1,3,10$ and $30 \mu \mathrm{g} / \mathrm{ml}$ ) of $70 \%$ hydroalcoholic and alkaloidal extracts of Murraya for $24 \mathrm{~h}$ and then cells were either stimulated with $10 \mu \mathrm{M}$ insulin or left untreated for $20 \mathrm{~min}$. After experimental incubation, cells were rinsed once with HEPES buffered Krebs Ringer phosphate solution ( $\mathrm{pH} 7.4$ ) and were subsequently incubated for 15 min in HEPES buffered solution containing $0.5 \mu \mathrm{Ci} / \mathrm{ml} 2$-deoxy-D- $\left[1-{ }^{3} \mathrm{H}\right]$ glucose. The uptake was terminated by aspiration of media. Cells were washed thrice with ice cold HEPES buffer solution and lysed in $0.1 \%$ sodium dodecyl sulphate (SDS). The lysates were transferred to the plate with glass fibre paper and allowed to air dry. This plate was used to measure the cell-associated radioactivity by liquid scintillation counter. All the assays were performed in duplicates and repeated thrice for concordance. Results have been expressed as \% glucose uptake with respective control.

\section{Palmitate induced insulin resistance assay ${ }^{20}$}

L6 cells were seeded in 96 well plates. Cells were maintained and differentiated for 9 days. Cells were starved for overnight and pre-treated with different concentrations ranging from $1,3,10$ and $30 \mu \mathrm{g} / \mathrm{ml}$ of aqueous extract of $70 \%$ hydroalcoholic and alkaloidal extracts of Murraya for $1 \mathrm{~h}$ at $37^{\circ} \mathrm{C} .0 .75 \mathrm{mM}$ Palmitate was added and incubated for $4 \mathrm{~h}$. During the period of incubation L6 cells were stimulated with $100 \mathrm{nM}$ insulin and $0.5 \mu \mathrm{Ci}$ of 2 -deoxy- $-{ }^{3}[\mathrm{H}]$ glucose uptake was analyzed following similar protocol of measuring radiolabelled glucose uptake.

\section{Anti - adipogenesis assay ${ }^{21}$}

3T3L1 pre-adipocytes were induced by the combination of IBMX, DEX and insulin to differentiate into adipocytes as previous described (day 0 ). $72 \mathrm{~h}$ after induction, the differentiation medium was replaced with $10 \%$ FBS-DMEM containing $1 \mathrm{mg} / \mathrm{l}$ insulin for $48 \mathrm{~h}$ (day 5). The medium was replaced again with fresh culture medium for $48 \mathrm{~h}$ (day 7). The degree of the differentiation of the cells was investigated by adding different 
solvent extracts of $70 \%$ hydroalcoholic and alkaloidal extracts of Murraya at doses of 3,10 and $30 \mu \mathrm{g} / \mathrm{ml}$ day 0 , a period which covered the entire induction and post induction stages. Before staining with oil red $\mathrm{O}$, cells were washed twice with PBS, fixed with $10 \%$ formaldehyde for $15 \mathrm{~min}$ at room temperature, washed twice with distilled water and once with $70 \%$ isopropanol. Next, cells were stained for $1 \mathrm{~h}$ at room temperature with filtered oil red $\mathrm{O}$ at a ratio of $60 \%$ oil red $\mathrm{O}$ stock solution $(0.5 \%$ $\mathrm{w} / \mathrm{v}$ in isopropanol) to $40 \%$ distilled water. The cells were washed twice with distilled water, twice with PBS, and examined under a microscope. Photomicroscopic evaluation was also carried out for the comparison of triglyceride accumulation using invertoscope (Nikon) was used for imaging at room temperature. For quantitative analysis, oil red $\mathrm{O}$ was extracted with isopropanol for $2 \mathrm{~min}$, and optical density of each sample was determined at $540 \mathrm{~nm}$.

\section{Advanced Glycation end product (AGE) assay ${ }^{22}$}

Bovine Serum Albumin (BSA) $(10 \mathrm{mg} / \mathrm{ml})$ was incubated with $1.1 \mathrm{M}$ fructose in $0.1 \mathrm{M}$ phosphate buffered-saline (PBS), $\mathrm{pH} 7.4$ containing $0.02 \%$ sodium azide in darkness at $37^{\circ} \mathrm{C}$ for 7 days. Before incubation, the solution containing different concentrations of $70 \%$ hydroalcoholic and alkaloidal extracts of Murraya were added to the mixtures. The glycated BSA formation was determined using fluorescent intensity at an excitation wavelength $355 \mathrm{~nm}$ and emission wavelength $460 \mathrm{~nm}$. Amino guanidine was used as a positive control for this study.

\section{HPTLC Standardization of Mahanine 23}

The 70\% hydroalcoholic and alkaloidal extracts of MK were prepared at a concentration of $25 \mathrm{mg} / \mathrm{ml}$ in Methanol. Standard Mahanine was prepared at concentration of $100 \mu \mathrm{g} / \mathrm{ml}$ in Methanol. Standard Mahanine was spotted at a range of 200ng - 1000ng and samples at two concentrations of $50 \mu \mathrm{g} / \mathrm{ml}$ and $100 \mu \mathrm{g} / \mathrm{ml}$ were spotted using CAMAG Linomat 5 applicator. The method was optimized by selecting appropriate mobile phase of n- hexane: ethyl acetate: glacial acetic acid (3:1:0.5) and developed in a twin trough chamber, $10 \times 10 \mathrm{~cm}$ at $25^{\circ} \mathrm{C}$. The plates were dried using hair dryer. The developed plates were scanned at $298 \mathrm{~nm}$ using CAMAG TLC scanner 3 and photo-documented using CAMAG REPROSTAR 3 at $254 \mathrm{~nm}$ and $366 \mathrm{~nm}$.

\section{Statistical analysis}

All the experiments were performed in triplicate and the results were expressed as Mean \pm SEM. One-way analysis of variance (ANOVA) was used to calculate the statistical significance of differences between groups for cell line based studies, followed by Tukey's test for multiple comparisons among groups using Graph Pad Prism v.5.0. $\mathrm{P}<0.05$ were considered as statistically significant. Linear regression analysis was done for in vitro extract based assays.

\section{RESULTS}

\section{Preliminary phytochemical analysis}

Preliminary phytochemical analysis showed the presence of phenolic compounds, flavones, and tannins, alkaloids, reducing sugars, proteins and carbohydrates in both the extracts (Table 1).

\section{In - vitro a - amylase and a-glucosidase inhibitory activities}

The, $70 \%$ hydroalcoholic and alkaloidal extracts of MK were evaluated for $\alpha$ - amylase and $\alpha$ - glucosidase inhibitory activity (Figure 1). The $70 \%$ hydroalcoholic extract of MK showed potent inhibitory activity against $\alpha$ - amylase enzyme with a maximum inhibition percentage of $92.23 \%$ at $1000 \mu \mathrm{g} / \mathrm{ml}$ which compared with standard Acarbose. The $\mathrm{IC}_{50}$ of $70 \%$ hydroalcoholic extract of MK was found to be $37.09 \mu \mathrm{g} / \mathrm{ml}$ which was found to be close enough to standard Acarbose whose $\mathrm{IC}_{50}$ is $34.83 \mu \mathrm{g} / \mathrm{ml}$. The alkaloidal extract showed its maximum inhibition percentage of $91.79 \%$ at $1000 \mu \mathrm{g} / \mathrm{ml}$ and its $\mathrm{IC}_{50}$ value was found to be
$48 \mu \mathrm{g} / \mathrm{ml}$. A similar inhibitory pattern was observed for MK extracts in case of $\alpha$ - glucosidase. The maximum inhibition of $\alpha$ - glucosidase of $70 \% \mathrm{HA}$ and alkaloidal extracts of MK was found to be $95.57 \%$ and $99 \%$ respectively whereas for Acarbose it was $97.29 \%$. The corresponding $\mathrm{IC}_{50}$ was found to be $21.56 \mu \mathrm{g} / \mathrm{ml}, 40.22 \mu \mathrm{g} / \mathrm{ml}$ and $42.11 \mu \mathrm{g} / \mathrm{ml}$ for $70 \% \mathrm{HA}$ MK extract, alkaloidal extract and Acarbose respectively.

\section{$\left[{ }^{3} \mathrm{H}\right]-2-D e o x y$ glucose (Radiolabelled) uptake assay}

Glucose uptake assay was carried out in differentiated L6 myotubes using radio - labelled glucose $\left[{ }^{3} \mathrm{H}\right]-2-$ Deoxy glucose. Incubation of L6 myotubes with different concentrations $(1,3,10$ and $30 \mu \mathrm{g} / \mathrm{ml})$ of $70 \% \mathrm{HA}$ and alkaloidal extracts of MK exhibited a dose - dependent increase in the glucose uptake activity which was comparable with that of Insulin (Figure 2). In the absence of insulin, 70\% HA extract of MK showed maximum glucose uptake of $65.80 \%$ at $30 \mu \mathrm{g} / \mathrm{ml}$ concentration, while the alkaloidal extract MK exhibited 55.99\% glucose uptake at the same concentration. The glucose uptake activity in both 70\% HA and alkaloidal groups in presence of insulin did not vary significantly compared to treatment without insulin. Hence it was revealed from the results that no additive or synergistic effect was exhibited by the MK extracts and insulin.

\section{Palmitate induced insulin resistance assay}

The effect of $70 \% \mathrm{HA}$ and alkaloidal extracts of MK was evaluated against Palmitate induced insulin resistance (Figure 3). Significant attenuation $(\mathrm{p}<0.001)$ of glucose uptake in L6 skeletal muscle cells was observed in Palmitate induced group due to insulin resistant condition. The $70 \%$ $\mathrm{HA}$ and alkaloidal extracts of MK at different concentrations (1, 3, 10 and $30 \mu \mathrm{g} / \mathrm{ml}$ ) exhibited dose - dependent increase in uptake of glucose by attenuating the effect of Palmitate. While insulin $(10 \mu \mathrm{M})$ exhibited $85.43 \%$ uptake of glucose, $70 \% \mathrm{HA}$ and alkaloidal extracts of MK showed maximum uptake of $67.23 \%$ and $61.12 \%$ of glucose at $30 \mu \mathrm{g} / \mathrm{ml}$.

\section{Oil O red adipogenesis assay}

The effect of 70\% HA and alkaloidal extracts of MK on lipid accumulation was investigated using 3T3L1 adipocytes at various doses of 1, 3, 10 and

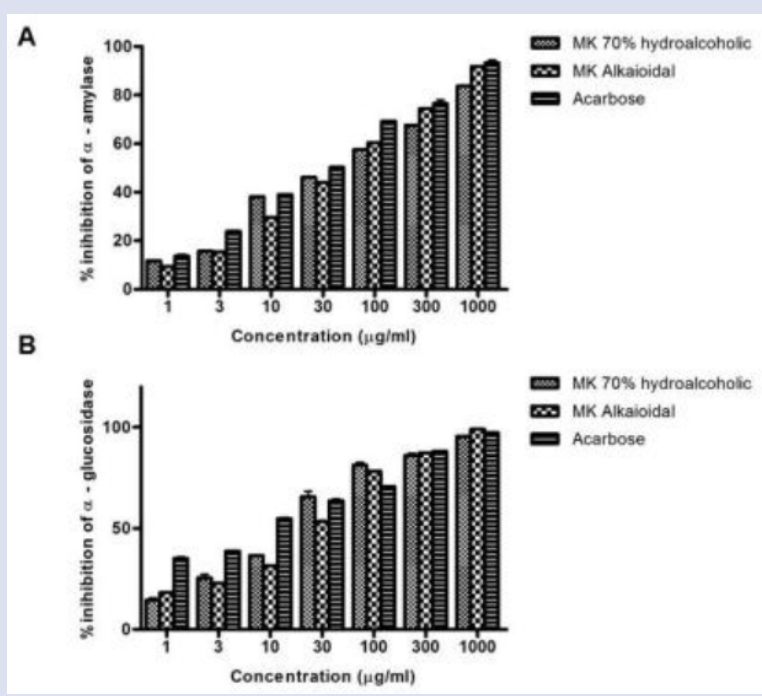

Figure 1: Effect of $70 \%$ hydroalcoholic and alkaloidal extracts of Murraya koenigii on (A) a - amylase inhibitory activity (B) a - glucosidase inhibitory activity compared with Standard Acarbose. All the data expressed as Mean \pm SEM of three independent experiments. 

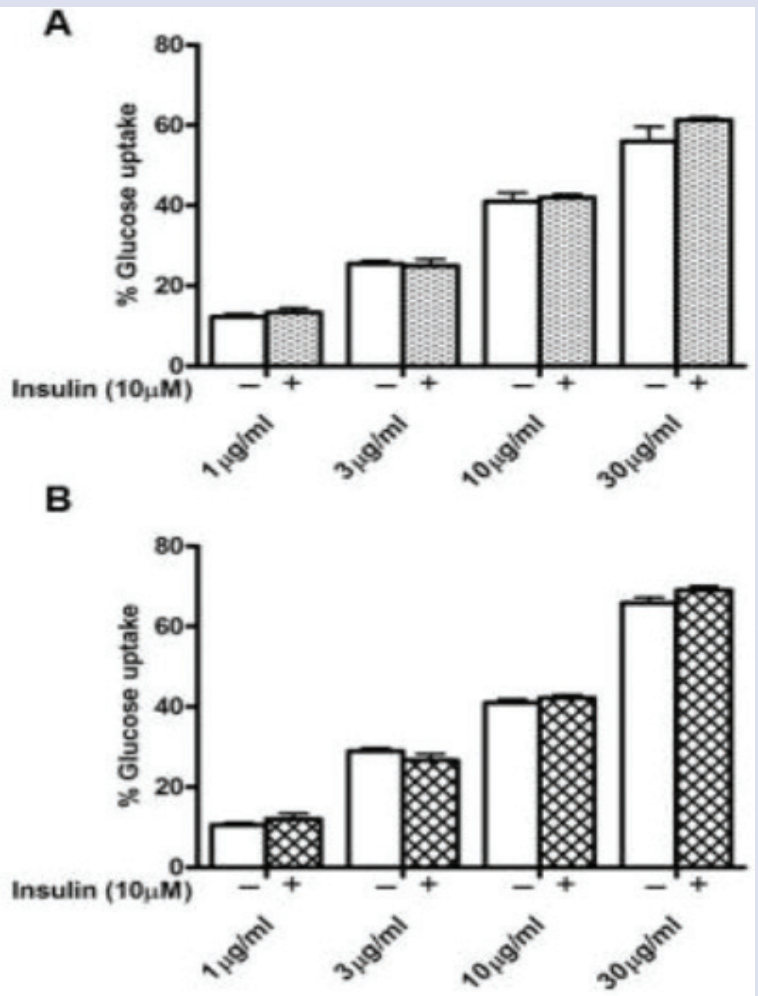

Figure 2: Dose response analysis of 70\% hydroalcoholic and alkaloidal extracts of Murraya koenigii on radiolabelled [3H]-2-Deoxy glucose uptake (A) without insulin and (B) with insulin using L6 myotubes. Cells were treated with different concentrations $(1,3$, 10 and $30 \mu \mathrm{g} / \mathrm{ml}$ ) of MK extracts. All the data expressed as Mean \pm SEM of three independent experiments. $P<0.05$ was considered statistically significant.

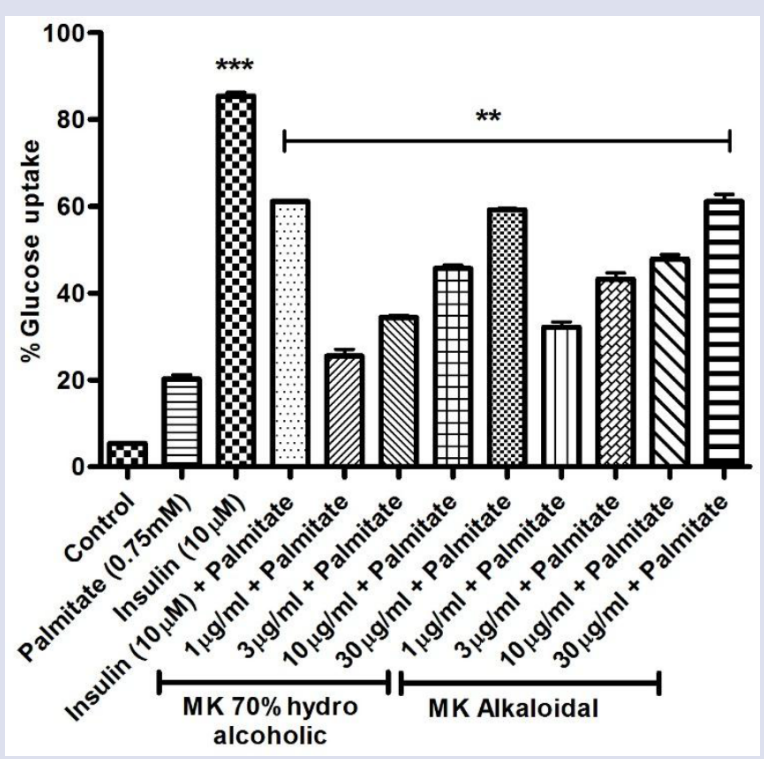

Figure 3: Effect of Palmitate on glucose uptake in L6 myotubes. L6 myotubes cultured in high glucose media with and without different concentrations of $70 \%$ hydroalcoholic and alkaloidal extracts of Murraya koenigii followed by incubation with $0.75 \mathrm{mM}$ Palmitate for $4 \mathrm{~h}$. Glucose uptake was measured using radiolabelled [3H]-2-Deoxy glucose. All the data expressed as Mean \pm SEM of three independent experiments. $\mathrm{P}<0.05$ was considered statistically significant.

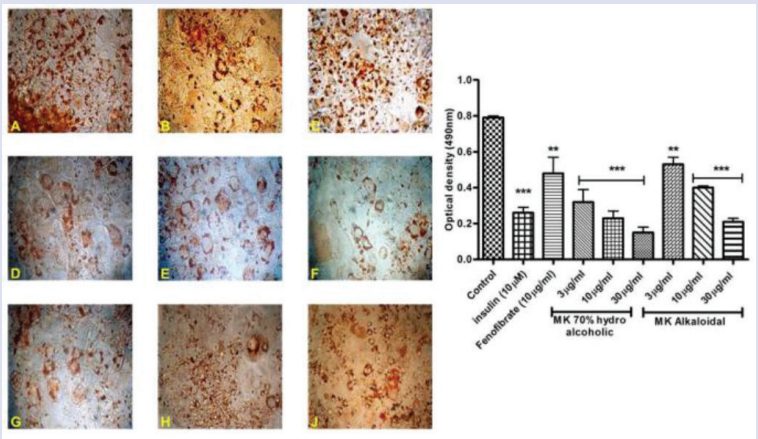

Figure 4: Effect of $70 \% \mathrm{HA}$ and alkaloidal extracts of Murraya koenigii on differentiated adipocytes. The adipocytes were stained using Oil O red (A) Differentiated adipocytes (B) Insulin $10 \mu \mathrm{M}(C)$ Fenofibrate $(10 \mu \mathrm{g} / \mathrm{ml})$ (D) $3 \mu \mathrm{g} / \mathrm{ml} 70 \%$ HA extract (E) $10 \mu \mathrm{g} / \mathrm{ml} 70 \% \mathrm{HA}$ extract (F) $30 \mu \mathrm{g} / \mathrm{ml} 70 \%$ HA extract (G) $3 \mu \mathrm{g} /$ $\mathrm{ml}$ alkaloidal extract (H) $10 \mu \mathrm{g} / \mathrm{ml}$ alkaloidal extract (I) $30 \mu \mathrm{g} / \mathrm{ml}$ alkaloidal extract. Bar graph represents relative density measured at $490 \mathrm{~nm}$ of accumulated lipid content. All the data expressed as Mean \pm SEM of three independent experiments. $P<0.05$ was considered statistically significant.

$30 \mu \mathrm{g} / \mathrm{ml}$ (Figure 4). Following eight days of differentiation, intracellular accumulation of lipid content was analysed by Oil $\mathrm{O}$ red staining. Increased lipid accumulation was visualized in control differentiated adipocytes indicated by increase in staining intensity. The 70\% HA and alkaloidal extracts of MK treated cells lowered triglyceride accumulation which was exhibited by decrease in staining pattern, suggestive of anti adipogenic property of the extracts.

\section{Diabetes associated complications assay - AGE product assay}

The potential of 70\% HA and alkaloidal extracts of MK were studied against AGE product inhibitory activity (Figure 5). Different doses of the extracts $(10,30,100,300$ and $1000 \mu \mathrm{g} / \mathrm{ml})$ were examined against AGE formation. The alkaloidal Murraya extract showed a considerable inhibition of $84 \%$ at a concentration of $1000 \mu \mathrm{g} / \mathrm{ml}$ while with $70 \% \mathrm{HA}$ extract of Murraya, inhibition was about $82 \%$ at the same concentration level. Gallic acid was used as positive control and it showed an inhibitory potential of about $73 \%$.

\section{HPTLC quantification of Mahanine in $70 \%$ hydroalcoholic and alkaloidal} extracts of $M K$

The HPTLC chromatograms of Mahanine, carbazole alkaloid are depicted in Figure 6. The retention factor $\left(\mathrm{R}_{\mathrm{f}}\right)$ of Mahanine in $70 \%$ hydroalcoholic and alkaloidal extracts of MK was found to be 0.73 . The quantification of Mahanine at scanning wavelength of $298 \mathrm{~nm}$ in the solvent system of n-hexane: ethylacetate: glacial acetic acid (3:1:0.5) demonstrated the presence of Mahanine in both the extracts. The percentage content of Mahanine in $70 \%$ hydroalcoholic and alkaloidal extracts of MK was found to be $19.68 \%$ and $26.59 \%$ respectively.

\section{DISCUSSION}

Diabetes is a chronic long - term metabolic disorder which is associated with persistent complications. Review of glycaemic control at regular time points with proper therapeutic treatment can develop control over the disorder. ${ }^{24}$ To devoid the adverse effects caused by modern medicines, options for complementary and alternative medicines have emerged. In this background, the results of the present study exemplify the effect 


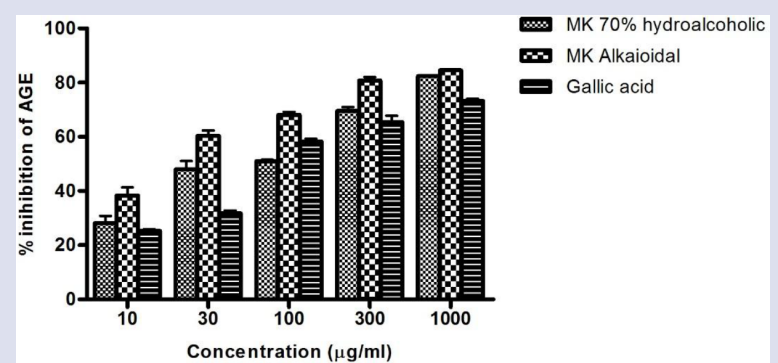

Figure 5: Effect of different concentrations of $70 \%$ hydroalcoholic and alkaloidal extracts of Murraya koenigii on inhibition of Advance glycation end products compared with standard amino guanidine. All the data expressed as Mean \pm SEM of three independent experiments. $P<0.05$ was considered statistically significant.

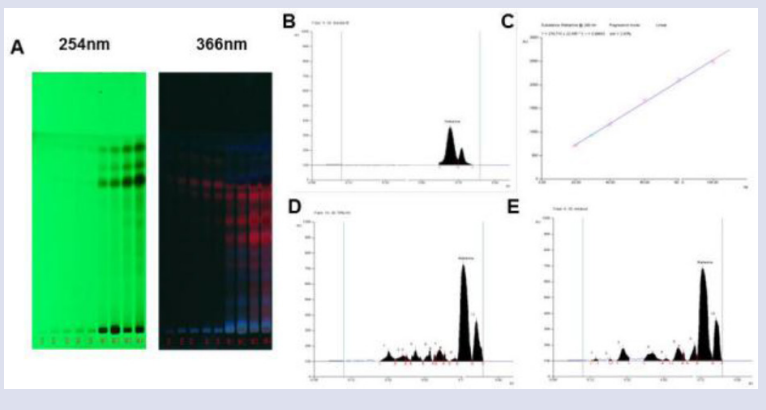

Figure 6: HPTLC chromatogram of Mahanine in 70\% HA and alkaloidal extracts of Murraya koenigii. Lanes 1 - 5 - Standard Mahanine $2 \mu \mathrm{l}-10 \mu \mathrm{l}$; Lane $6-2 \mu \mathrm{l}$ of $70 \% \mathrm{HA}$ extract; Lane $7-4 \mu \mathrm{l}$ of $70 \%$ HA extract; Lane $8-2 \mu \mathrm{l}$ of alkaloidal extract; Lane $9-4 \mu \mathrm{l}$ of alkaloidal extract. (A) Photo document showing presence of Mahanine at $254 \mathrm{~nm}$ and $366 \mathrm{~nm}$ (B) Standard Mahanine (C) Std. Calibration Curve (D) Peak area of Mahanine in 70\% HA extract (E) Peak area of Mahanine in alkaloidal extract. Mobile phase: $n$ hexane: Ethyl acetate: Glacial acetic acid [3:1:0.5]; Scanning wavelength: $298 \mathrm{~nm}$; $R_{f}$ value: 0.73 .

of Murraya extracts on carbohydrate metabolizing enzymes, glucose uptake potential, insulin resistance, and adipogenesis as well as on diabetesassociated complications.

Hyperglycemia is one of the hallmark features of T2D; hence regulating plasma glucose plays a crucial role in preventing T2D. $\alpha$ - amylase and $a$ - glucosidase are the two key enzymes that are responsible for postprandial hyperglycemia. Hence inhibiting the activity of these enzymes would be one of the best approaches in the management of diabetes, as it delays the absorption of ingested carbohydrates. ${ }^{25}$ The results of our present study exhibited that aqueous, absolute alcohol, 70\% hydroalcohol and alkaloidal extract of MK have effectively inhibited these enzymes which suggests that Murraya koenigii possess carbohydrate metabolism regulating property, thereby beneficial in reducing postprandial glucose. Skeletal muscle is the predominant regulatory site for insulin stimulated glucose uptake which helps in maintenance of glucose homeostasis. Major portion of glucose is stored in muscle cells as glycogen; it is considered as target tissue to investigate on T2D and its complications. Impaired insulin action concomitant with decreased glucose uptake is
Table 1: Preliminary Phytochemical analysis of $70 \%$ hydroalcoholic (HA) and alkaloidal MK extracts showing presence of various phytoconstituents.

\begin{tabular}{cccc}
\hline S.NO & CHEMICAL & \multicolumn{2}{c}{ Murraya koenigii } \\
CONSTITUENTS & $\begin{array}{c}\text { 70\% Hydroalcohol } \\
\text { extract }\end{array}$ & $\begin{array}{c}\text { Alkaloidal } \\
\text { extract }\end{array}$ \\
\hline 1 & Phenolic compounds & +++ & +++ \\
2 & Reducing sugars & +++ & +++ \\
3 & Carbohydrates & +++ & +++ \\
4 & Flavones & ++ & ++ \\
5 & Glycosides & +++ & +++ \\
6 & Saponins & ++ & ++ \\
7 & Steroids & - & + \\
8 & Alkaloid & +++ & +++ \\
9 & Quinones & +++ & +++ \\
10 & Proteins & ++ & ++ \\
11 & Tannins & ++ & ++ \\
\hline
\end{tabular}

+++ = High; ++ = Moderate; + = Mild; - = absent

characteristic of skeletal muscle insulin resistance. ${ }^{26}$ Quite a few reports on anti - diabetic effect of alkaloids, especially Carbazole alkaloids from Murraya have been reported..$^{27-30}$ Corroborating the previous reports, the present study results revealed the potential of $70 \%$ hydroalcoholic and alkaloidal extract of MK in augmenting glucose uptake by attenuating the effect of Palmitate induced insulin resistance, proposing that Carbazole alkaloids present in the extracts might be the contributing factor for the anti - hyperglycemic effect.

Synthesis and storage of lipids, in the form of triglycerides is the primary function of adipocytes. Adipogenesis is a process that encompasses increased growth of adipocyte mass, adipocyte differentiation and accumulation of lipid in adipocytes, factors that leads to obesity condition. ${ }^{31}$ Hence inhibiting adipogenesis would be one of the best strategies for the management of obesity. Herbal extracts enriched with polyphenols, alkaloids etc., possess potent anti - adipogenic and hypoglycemic activities. ${ }^{32}$ Our study results exhibited decreased lipid content in $70 \%$ HA and alkaloidal extracts treated group, indicative of adipogenesis inhibition in 3T3L1 adipocytes, which signifies the anti - obesity effect of MK.

Metabolic imbalance in T2D results in generation of reactive oxygen species (ROS) which decreases the antioxidant levels. This leads to increased oxidative stress which in turn, activates the polyol pathway. Activation of polyol pathway leads to increased production of intracellular sorbitol and fructose, thereby increasing the production of AGEs. ${ }^{33}$ Hence, any compound which possesses the property of inhibiting both these activities may be beneficial. Studies have demonstrated that plants rich in flavonoids possess aldolase inhibitory property, ${ }^{34,35}$ whereas plants enriched with alkaloids have shown potent AGE inhibitory property. ${ }^{36}$ $70 \%$ hydroalcoholic and alkaloidal extracts of MK effectively inhibited the formation of AGE, which may be due to the presence of carbazole alkaloids.

\section{CONCLUSION}

Results of our study demonstrate multiple effects of Murraya koenigii in the management of diabetes as well as its associated complications, 
thereby suggesting that the effective bioactive ingredients present in MK can be used for future research, both in vitro and in vivo and evaluate its antidiabetic activity by exploring the underlying mechanisms.

\section{ACKNOWLEDGEMENT}

The authors wish to thank the Drugs and Pharmaceutical division, Department of Science and technology, New Delhi for the research grant.

\section{CONFLICT OF INTEREST}

The authors declare no conflict of interest.

\section{ABBREVIATIONS}

IR: Insulin resistance; T2D: Type 2 diabetes; MK: Murraya koenigii; HA: hydroalcoholic; CCRAS: Central Council for Research in Ayurveda and Siddha; NCCS: National Centre for Cell Science; DMEM: Dulbecco's Modified Eagle's Medium; FBS: Fetal bovine serum; IBMX: 3-isobutyl1-methylxanthine; DEX: Dexamethasone; PBS: Phosphate buffered Saline; AGE: Advanced Glycation End Product; HPTLC: High Performance Thin Layer Chromatography; ROS: Reactive oxygen species.

\section{REFERENCES}

1. Chiasson JL, Rabasa-Lhoret R. Prevention of type 2 diabetes: insulin resistance and beta-cell function. Diabetes. 2004;53(3):S34-8.

2. Juarez-Reyes K, Brindis F, Medina-Campos ON, Pedraza-Chaverri J, Bye R, Linares $\mathrm{E}$, et al. Hypoglycemic, antihyperglycemic, and antioxidant effects of the edible plant Anoda cristata. J Ethnopharmacol. 2015;161:36-45

3. Perera PK, Yunman Li. Functional herbal food ingredients used in type 2 diabetes mellitus. Pharmacogn Rev. 2012;6(11):37-45.

4. Jain V, Momin M, Laddha K. Murraya Koenigii: An Updated Review. IJAHM 2012; 2(4):607-27.

5. Nagappan T, Chandra segaran T, Abdul Wahid ME, Ramasamy P, Vairappan SC. Efficacy of Carbazole Alkaloids, Essential Oil and Extract of Murraya koenigii in Enhancing Subcutaneous Wound Healing in Rats. Molecules. 2012;17(12):14449-63.

6. Satyavati GV, Gupta AK, Tandon N. Medicinal Plants of India. ICMR. 1999;2:289-99.

7. Tachibana $Y$, Kikuzaki H, Lajis NH, Nakatani N. Comparison of Anti Oxidative Properties Of Carbazole Alkaloids From Murraya koenigii Leaves. J Agric Food Chem. 2003;51(22):6461-7.

8. Aqil F, Ahamad I. Broad Spectrum antibacterial and antifungal properties of certain traditionally used Indian Medicinal plants. World J Microb Biotech. 2003;19(6):653-7.

9. Maiti AK, Dash GK, Patro CP. Anti-inflammatory and analgesic activity of leaf essential oil from Murraya koenigii Spreng. Hamdard Med. 2004;47(2):22-6.

10. Powers SK, Deruisseau KC, Quindry J, Hamilton KL. Dietary antioxidants and exercise. J Sports Sci. 2004;2(1):81-94.

11. Vinuthan MK, Girish KV, Ravindra JP, Jayaprakash, Narayana K. Effect of extracts of Murraya koengii leaves on levels of blood glucose and plasma insulin in alloxan-induced diabetic rats. Indian J Physiol Pharmacol. 2004;48(4):348-52.

12. Kesari N, Gupta RK, Watal G. Hypoglycemic effects of Murraya koenigii on normal and alloxan-diabetic rabbits. J Ethnopharmacol. 2004;97(2):247-51.

13. Tembhurne SV, Sakarkar DM. Protective effect of Murraya koenigii (L) leaves extract in streptozotocin induced diabetic's rats involving possible antioxidant mechanism. J Med Plants Res. 2010;4(22):2418-23.

14. Kar A, Choudhary BK, Bandyopadhyay NG. Preliminary studies on the inorganic constituents of some indigenous hypoglycaemic herbs on oral glucose tolerance test. J Ethnopharmacol. 1999;64(2):179-84.

15. Adebajo AC, Olayiwola G, Eugen VJ, Iwalewa EO, Omisore NOA Bergenthal $\mathrm{D}$, et al. Evaluation of the Ethnomedical Claims of Murraya koenigii. Pharm Biol. 2005;42(8):610-20.
16. Yadav S, Vats V, Dhunnoo Y, Grover JK. Hypoglycemic and antihyperglycemic activity of Murraya koenigii leaves in diabetic rats. J Ethnopharmacol. 2002;82(2):111-6.

17. Harborne JB. Phytochemical methods. Chapman and Hall publications, $2^{\text {nd }}$ Ed New York. 1988;288.

18. Bernfeld P. Amylases $\alpha$ and $\beta$ in: Methods in Enzymology, Clowick SP and Kaplan NO, Editors. Academic Press Inc Publishers. New York. 1955;149-58.

19. Sanchetia S, Sanchetia S, Lee SH, Lee JE, Seo SY. Screening of Korean Medicinal Plant Extracts for $\alpha$-Glucosidase Inhibitory Activities. Iran J Pharm Res. 2011;10(2):261-4.

20. Anand S, Muthusamy VS, Sujatha S, Sangeetha KN, Bharathi Raja R, Sudhagar S et al. Aloe emodin glycosides stimulates glucose transport and glycogen storage through PI3K ependent mechanism in L6 myotubes and inhibits adipocyte differentiation in 3T3L1 adipocytes. FEBS Letters. 2010;584(14):3170-8.

21. Gupta SD, Bhattacharya S, Maitra S, Pal D, Majumdar SS, Datta A, et al. Mechanism of lipid induced insulin resistance: Activated PKCE is a key regulator. Biochim Biophys Acta. 2011;1812(4):495-506.

22. Harris CS, Beaulieu LP, Fraser MH, Mclntyre KL, Owen PL, Martineau LC, et al. Inhibition of advanced glycation product formation by medicinal plant extracts correlates with phenolic metabolites and antioxidant activity. Planta Med. 2011;77(2):196-204.

23. Wagner H, Bladt S. Plant Drug Analysis - A Thin Layer Chromatography Atlas. 2nd Ed. Berlin: Springer-Verlag. 1996;384.

24. Deutschlander MS, Van de Venter M, Roux S, Louw J, Lall N. Hypoglycaemic activity of four plant extracts traditionally used in South Africa for diabetes. J Ethnopharmacol. 2009;124(3):619-24.

25. Tiwari AK, Rao M. Diabetes mellitus and multiple therapeutic approaches of phytochemicals: Present status and prospects. Curr Sci. 2002;83(1):10.

26. Tamrakar AK, Jaiswal N, Yadav PP, Maurya R, Srivastava AK. Pongamol from Pongamia pinnata stimulates glucose uptake by increasing surface GLUT4 level in skeletal muscle. Mol Cell Endocrinol. 2011;339(1):98-104.

27. Cheng $Z$, Pang T, Gu M, Gao AH, Xie CM, Li JY, et al. Berberine-stimulated glucose uptake in L6 myotubes involves both AMPK and p38 MAPK. Biochim Biophys Acta. 2006;1760(11):1682-9.

28. Gulfraz M, Mehmood S, Ahmad A, Fatima N, Praveen Z, Williamson EM. Comparison of the antidiabetic activity of Berberis lyceum root extract and berberine in alloxan-induced diabetic rats. Phytother Res. 2008;22(9):1208-12.

29. Dineshkumar B, Mitra A, Manjunatha M. Antidiabetic and hypolipidemic effects of mahanimbine (carbazole alkaloid) from Murraya koenigii (Rutaceae) Leaves. Int J Phytomed. 2010;2(1):22-30.

30. Patel OP, Mishra A, Maurya R, Saini D, Pandey J, Taneja I, et al. Naturally Occurring Carbazole Alkaloids from Murraya koenigii as Potential Antidiabetic Agents. J Nat Prod. 2016;79(5):1276-84.

31. Hsu CL, Yen GC. Induction of cell apoptosis in 3T3-L1 pre-adipocytes by flavonoids is associated with their antioxidant activity. Mol Nutr Food Res. 2006;50(11):1072-9

32. Li KK, Liu CL, Shiu HT, Wong HL, Siu WS, Zhang C, et al. Cocoa tea (Camellia ptilophylla) water extract inhibits adipocyte differentiation in mouse 3T3-L1 preadipocytes. Sci Rep. 2016;6:20172.

33. Gupta P, Jain V, Pareek A, Kumari P, Singh R, Agarwal $P$, et al. Evaluation of effect of alcoholic extract of heartwood of Pterocarpus marsupium on in vitro antioxidant, anti-glycation, sorbitol accumulation and inhibition of aldose reductase activity. J Tradit Complement Med. 2016;7(3):307-14

34. Patil UH, Dattatraya KG. Pterocarpus marsupium: a valuable medicinal plant in diabetes management. Int J App Bio Pharm Tech. 2011;2:6-13.

35. Hilal A, Kalyanaraman R. Pharmacology of Pterocarpus marsupium Roxb. Med Plant Res. 2015;5:1-6

36. Maqsood AS, Saima Rasheed, Quaiser Saquib, Al-Khedhairy AA, Al-Said MS, Javed Musarrat C. In-vitro dual inhibition of protein glycation, and oxidation by some Arabian plants. BMC Complementary and Alternative Medicine. $2016 ; 16(1): 276$.

Cite this article: Parameswari RP, Janani M, Dinesh, MG, Srivani T, Chamundeeswari D, Thyagarajan SP. Hydroalcoholic and Alkaloidal Extracts of Murraya koenigii (L.) Spreng Augments Glucose Uptake Potential against Insulin Resistance Condition in L6 Myotubes and Inhibits Adipogenesis in 3T3L1 Adipocytes. Pharmacog J. 2018;10(4):633-9. 
GRAPHICAL ABSTRACT

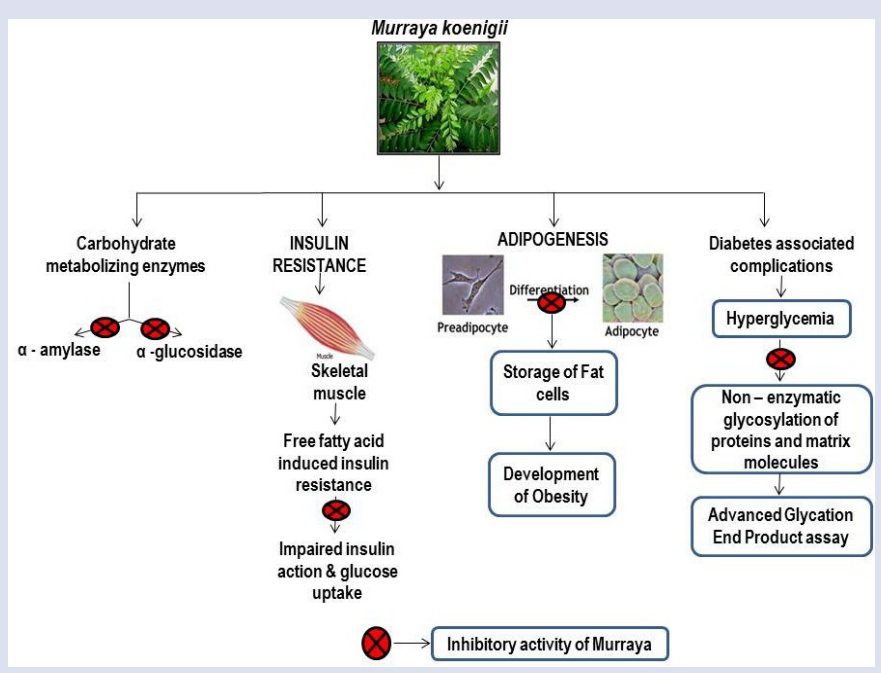

SUMMARY

- The $70 \%$ hydroalcoholic and alkaloidal extract exhibited beneficial effect against insulin resistance and adipogenesis.

- The extracts were found to be effective not only on obesity and type 2 diabetes but were also potent enough in prevention of diabetes associated complications.

- The anti - diabetic effect of Murraya koenigii might be attributed to the presence of major phyto constituent Mahanine, carbazole alkaloid present. 